Article

\title{
Serum Total Cholesterol and Triglyceride Status in Female Athletes
}

\author{
Dilruba Akther ${ }^{1}$, Ruhul Amin ${ }^{2}$, Umme Sultana Naima Begum $^{3}$, Najneen Akhter ${ }^{4}$ Nasrin Habib ${ }^{5}$, \\ Muntasir Islam ${ }^{6}$, Abidur Rahman ${ }^{7}$.
}

\begin{abstract}
Background: Exercise plays a role in preventing cardiovascular disease as well as other serious health problems. Objectives: A cross sectional comparative study was performed to observe the changes in serum total cholesterol and triglyceride in apparently healthy female athletes. Methods This study was carried out in the Department of Physiology of Dhaka Medical College from July 2005 to June 2006. For this, 30 female athletes aged 17 to 38 years (experimental) who were under regular physical exercise training for at least two years and age matched 30 healthy female non athletes (control) for comparison were selected. Fasting serum Triglyceride and total Cholesterol levels of all the subjects were measured. Data were compared between athletes and non athletes and analyzed statistically by unpaired ' $t$ ' test. Results Mean \pm SD cholesterol levels were $141.10 \pm 14.46 \& 165.10 \pm 7.03$ and Mean \pm SD Triglyceride levels were $76.10 \pm 11.54$ \& 96.60 \pm 17.02 in athletes and non athletes respectively. Serum total cholesterol $(\mathrm{p}<0.001)$ and triglycerides $(\mathrm{p}<0.01)$ were significantly lower; in athletes compared to those of non athlets. Conclusion: From this study it can be concluded that, serum total cholesterol and triglycerides may be lowered in athletes.
\end{abstract}

Key words: Female athletes, Cholesterol, Triglyceride.

J Bangladesh Soc Physiol. 2010 December; 5(2): 71-74 For author affiliations, see end of text.

http://www.banglajol.info/index.php/JBSP

\section{Introduction}

$\mathbf{P}$ hysical activity can be looked upon as nourishment for the body, mind and soul, just as food can be ${ }^{1}$. Regular physical activity using large muscle group, such as walking, running, or swimming, produces cardiovascular adaptation that increase exercise capacity, endurance, and skeletal muscle strength $^{1}$. Exercise is a subset of physical activity that is planned, structured, repetitive, and purposeful in the sense that improvement or maintenance of physical fitness is the objectives 2. It plays a role in preventing cardiovascular disease as well as other serious health problems and exerts both acute $\&$ chronic effects on plasma lipid \& lipoprotein concentration ${ }^{2}$. During endurance training, endogenous TG can be broken down into fatty acids by lipolysis and enter the muscle fiber where they can serve as a fuel for muscle contraction ${ }^{3}$. During light exercise fat can provide most of the energy used by exercising muscle; whereas during long duration exercise intramuscular triglycerides (IMTG) represents a potentially important energy source for contracting human skeletal muscle ${ }^{4}$.

Numerous studies have been reported that hypercholesterolemia, hyper-tri-glyceridaemia or both carry an increased risk of developing premature coronary artery disease ${ }^{5}$. Hypercholesterolemia is one of the major risk factor for coronary atherosclerosis, and some evidence suggests that triglycerides are 
independent risk factor only in women ${ }^{4-6}$. Triglyceride are listed as cardiovascular risk factor in the National Cholesterol Education Programmed guidelines, by contrast, the European classification of hyper-lipidaemia is based on simultaneous measurements of both cholesterol and triglycerides ${ }^{5}$.

The rationale of this study was based on the effect of exercise on serum cholesterol and triglyceride in order to observe its effects to minimize any cardiovascular diseases and other complications.

\section{Methods}

The present cross sectional study was carried out in the Department of Physiology, Dhaka Medical College, Dhaka, from June 2005 to July 2006. In this study, 30 female athletes with age ranged from 17 to 38 years were included in experimental group (group A). They were selected from Sultana Kamal Women sports Complex, Dhanmondi Dhaka. 30 age matched apparently heaithy female subjects were included in control group (group B). They were selected from different hall of Dhaka university. All the subjects belong to middle socioeconomic class. The subjects were excluded for any endocrine, hepatic disease, diabetes mellitus, renal disease, cardiopulmonary diseases, history of drugs intake such as $\beta$ blocker, lipid lowering drugs, steroid therapy, obesity and alcohol intake. Before inclusion into the study all ethical considerations for the subjects were taken into account. The aim and benefit of the study were explained to each subject and they were encouraged for voluntary participation. A written informed consent was obtained from each subject. A thorough clinical examination of all subjects were done and detailed medical, family, personal and dietary history and detailed information about physical activity were recorded in prefixed questionnaire. The subjects were advised for 12 hours overnight fasting. In the morning $5 \mathrm{ml}$ venous blood was drawn under proper aseptic precaution and serum was prepared by centrifugation and sent to the laboratory. Serum total cholesterol and triglyceride were determined by Dade Bering Dimension RXL method a standard laboratory. Data were expressed as mean and standard deviation. Statistical analysis was done by unpaired student's “ $t$ ” test.

\section{Results}

The anthropometric parameters of all study subjects are presented in Table-I. No statistically significant differences were observed between the groups in relation to age, height, body mass index (BMI) of the subjects.

Mean serum total cholesterol and triglyceride were significantly lower $(\mathrm{p}<0.001 ; \mathrm{p}<0.01)$ in experimental group than that of control. (Table II).

Table I: Mean \pm SD of Age, Height, Weight and BMI in different groups of study subjects ( $n=60)$

\begin{tabular}{lccccc}
\hline Group & $\mathrm{n}$ & $\begin{array}{c}\text { Age } \\
(\text { Year})\end{array}$ & $\begin{array}{c}\text { Height } \\
(\mathrm{Cm})\end{array}$ & $\begin{array}{c}\text { Weight } \\
(\mathrm{Kg})\end{array}$ & $\begin{array}{c}\text { Body mass index } \\
(\mathrm{BMI})\end{array}$ \\
\hline A & 30 & $24.50 \pm 2.22$ & $166.60 \pm 3.57$ & $48.00 \pm 4.29$ & $17.29 \pm 1.33$ \\
B & 30 & $24.20 \pm 2.25$ & $164.10 \pm 2.28$ & $51.70 \pm 6.31$ & $19.25 \pm 2.66$ \\
\hline
\end{tabular}

P values were obtained by unpaired ' $t$ ' test. Values in parenthesis indicate ranges.

Group-A: Experimental (athletes)

Group-B: Control (non athletes)

$\mathrm{n}=$ number of subject

$*=<0.05$

J Bangladesh Soc Physiol. 2010 December; 5(2): 71-74 
Table II: Mean \pm SD of Serum Cholesterol and TG in different groups of study subjects $(\mathrm{n}=60)$

\begin{tabular}{lccc}
\hline Variable & Group-A $(\mathrm{mg} / \mathrm{dl})$ & Group-B $(\mathrm{mg} / \mathrm{dl})$ & $\mathrm{P}$ value \\
\hline Serum Cholesterol & $141.10 \pm 14.46$ & $165.10 \pm 7.03$ & $<0.001^{* * *}$ \\
TG & $76.10 \pm 11.54$ & $96.60 \pm 17.02$ & $<0.01^{* *}$ \\
\hline
\end{tabular}

P values were obtained by unpaired' $t$ ' test. Values in parenthesis indicate ranges.

Group-A: Experimental (athletes)

Group-B Control (non athletes)

$*=<0.05$

\section{Discussion}

In the present study the observed significantly lower total cholesterol and triglyceride levels in athletes were almost similar to those reported by other workers in different countries ${ }^{4,7,8}$. Regular exercise decrease adiposity with weight reduction, which causes lowering of serum total cholesterol, as adiposity is positively associated with serum cholesterol $^{2,9}$. Vigorous exercise has been followed by moderate reduction of serum total cholesterol concentration ${ }^{2}$.

Low triglyceride level in athletes was due to hydrolysis of intra muscular triglyceride (IMTG), decrease hepatic triglyceride synthesis and increased lipoprotein lipase activity ${ }^{4,7}$.In exercise a variety of hormones influences energy metabolism of considerable importance which are the catecholamines and insulin ${ }^{5,10}$.The most dramatic increase in fat utilization that is observed during heavy exercise is due to release of catecholamines by the adrenal medulla ${ }^{10}$. Epinephrine and nor epinephrine directly activate hormone sensitive lipase, which is present in abundance in the fat cell and this causes rapid breakdown of triglycerides and mobilization of fatty acids ${ }^{1,5}$. Results of this study shows significant changes in both mean serum total cholesterol and TG probably because of lipoprotein lipase (LPL) activity, which was regulated by the balance between hormones that stimulate (primarily catecholamine's) and those that inhibit enzyme hormone-sensitive lipase (primarily insulin), and the action was mediated by increased $\beta$ adrenergic stimulation, which hydrolyses triacylglycerols to fatty acids and glycerol ${ }^{1,2,7}$. Exercise lowers triglycerides by increasing insulin receptor activity and reduces abdominal body fat ${ }^{7}$.

Exercise involved in increasing the production and action of several enzyme that function to enhance the reverse cholesterol transport system $^{9}$. Potential mechanism by which exercise modifies plasma lipid and lipoprotein profile were related to increase in lipoprotein lipase (LPL) and lecithin cholesterol acagl transferase (LCAT) activity $^{8}$.

\section{Conclusion}

Regular physical exercise may lower the serum total cholesterol and triglyceride level in female athletes.

\section{Acknowledgement}

The author of this article are thankful to the authority of Sultana Kamal Women Sports Complex Dhanmondi, Dhaka for their cooperation. 


\section{Author Affiliations}

1. Dr Dilruba Akther, Assistant Professor, Department of Physiology, Holy Family Red Crescent Medical College, Dhaka., Phone : 01911934319 E-mail: dilrubaakther82@yahoo.com

2. Professor Ruhul Amin, Professor \& Head, Department of Physiology, MAG Osmany Medical College, Sylhet.

3. Professor US Naima Begum MBBS, M Phil, Professor \& Head, Department of Physiology, Holy Family Red Crescent Medical College, Dhaka. Phone:01911392699 E-mail :dr_naimabegum@ yahoo.com

4. Dr Najneen Akhter Associate Professor, Department of Physiology Holy Family Red Crescent Medical College, Dhaka.Phone: 01711174174

5. Dr. Nasrin Habib, Assistant Professor, Department of Physiology, Holy Family Red Crescent Medical College, Dhaka. Phone: 07711937853

6. Dr. Montasir Islam, Associate Professor, Department of Physiology, Comilla Central Medical College, Comilla.Phone: 07177330990 E-mail: montasir_dr@yahoo.com

7. Dr. Abidur Rahman, Lecturer Microbiology department, Dhaka Medical College, Dhaka. Phone: 01819050041

\section{References}

1. Thompson PD, Bucher D, Pina IL, Balady GJ, Williams MA. Exercise And Physical Activity In The Prevention \& Treatment Of Atherosclerotic Cardiovascular Diseases. Am. College of Sport Med. 2003; 23 : e42.

2. Haskell WL. The Influence Of Exercise On The Concentrations Of Triglyceride And Cholesterol In Human Plasma. Exerc and Sport Sci. Rev. 1984; 12: 205-44
3. Axen K,Vermitsky K. Illustrated Principles Of Exercise Physiology. New Jersey: Prentice Hall. 2001: 207p.

4. Dowling EA. How Exercise Affects Lipid Profile In Women. The Physician and Sport. Med. 2001; 29(9):1-8.

5. Gotto AM, Gorry GA, Thompson JR, Cole JS, Trost R, Yeshirur D. Relationship Between Plasma Lipid Concentrations And Coronary Disease In 496 Patients. Circulation. 1977;56: $876-83$.

6. Rahman A, Ali A, Salam A, Hossain M, Mallah R, Rahman S, et al Relation Between Hypertriglyceridemia And Decrease High Density Lipoproteins With Coronary Artery Disease”. J. inst. Postgrad. Med. Res. 1998; 13(1): 5-8.

7. Rahman BM, Ali SM. A Comparative Study Of Serum Lipid Profile In Active And Retired Athletes. Bangladesh J. Physiol and Pharmacol. 1995; 10(20): 60- 62 .

8. Kravitz L, Vella C.A. Energy Expenditure In Different Modes Of Exercise. Am College of Sport. Med. 2002; June;

9. Durstine J.L, Haskell W.L. Effects Of Exercise Training On Plasma Lipids And Lipoproteins. Exerc and Sport Sci Rev. 1994; 22: 477 - 22.

10. Guyton AC, Hall JE, : Text book of Medical Physiology. $11^{\text {th }}$ ed. Philadelphia: Elsevier; 2006: 502p.

11. Watt MJ, Heigenhauser GJF, Spriet LL. Intramuscular Triacylglycerol Utilization In Human Skeletal Muscle During Exercise : Is There A Controversy ? J. of Appl Physiol. 2002; 93 : 1185 -95 . 